\title{
COMPLICAÇÕES URETERAIS NOS TRANSPLANTES RENAIS PEDIÁTRICOS; ANÁLISE DE 84 PACIENTES OPERADOS NA SANTA CASA DE SÃO PAULO ENTRE 1985 E 2005
}

\author{
Ureteral Complications after Pediatric Kidney Transplantation: Observations in 84 Patients at Santa \\ Casa of São Paulo
}

\begin{abstract}
Luiz Renato Montez Guidoni', Fernando Korkes', Roni de Carvalho Fernandes², Mozart Queiroz ${ }^{3}$, Augusto Modesto ${ }^{4}$, Eduardo Taromaru ${ }^{3}$, Simone Laranjo ${ }^{5}$, Vanda Benini ${ }^{6}$, Marjo Cardenuto Perez
\end{abstract}

\begin{abstract}
RESUMO
Introdução: As principais complicações ureterais são: fístula, estenose e refluxo, variando de 2 a $10 \%$, sendo rara a evolução para perda do enxerto ou óbito. Objetivo: Analisar as complicações ureterais nos pacientes pediátricos submetidos a transplante renal, relacionando com a sobrevida do paciente e do enxerto. Métodos: Estudo transversal retrospectivo com 84 casos consecutivos de transplantes renais pediátricos na Santa Casa de São Paulo entre Out/1985 a Abr/2005, com idades de um a 17 anos. Resultados: Dos 84 pacientes, nove apresentaram complicações ureterais (10,7\%), sendo oito fístulas $(9,5 \%)$ e uma estenose ureteral $(1,1 \%)$. Todas as fístulas ocorreram entre o segundo e o trigésimo sexto dia pós-operatório, em média, no décimo primeiro dia. Não houve casos de refluxo vésico-ureteral para o rim transplantado. Em apenas dois dos nove pacientes (1,7\%) ocorreu perda do enxerto após o primeiro ano do transplante. Conclusão: Estas complicações ureterais não interferem diretamente na sobrevida do paciente e do enxerto.
\end{abstract}

Descritores: Complicações; ureter; transplante; renal; intervivos; infantil.

Trabalho realizado na Disciplina de Urologia do Departamento de Cirurgia da Santa Casa de São Paulo.

1. Residente de Urologia da Santa Casa de São Paulo, Membro aspirante da Sociedade Brasileira de Urologia.

2. Mestre em Urologia pela Santa Casa de São Paulo, Professor assistente da disciplina de urologia da Santa Casa de São Paulo, Membro Titular da Sociedade Brasileira de Urologia, Membro associado da Associação Brasileira de Transplante de Órgãos.

3. Residente de Cirurgia Geral da Santa Casa de São Paulo

4. Assistente da disciplina de Urologia da Santa Casa de São Paulo, Membro Titular da Sociedade Brasileira de Transplante de Órgãos.

5. Mestre em Nefrologia Pediátrica pela Santa Casa de São Paulo, Assistente da disciplina de nefrologia pediátrica da Santa Casa de São Paulo.

6. Mestre em Nefrologia Pediátrica pela Escola Paulista de Medicina, Doutora em Nefrologia Pediátrica pela Santa Casa de São Paulo, Chefe da disciplina de nefrologia pediátrica da Santa Casa de São Paulo.

7. Professor Doutor em Urologia pela Santa Casa de São Paulo, Chefe da disciplina de Urologia da Santa Casa de São Paulo, Professor adjunto do departamento de cirurgia da Santa Casa de São Paulo, Membro Titular da Sociedade Brasileira de Urologia.

Instituição:

Disciplina de Urologia do Departamento de Cirurgia da Santa Casa de São Paulo

Autor responsável/correspondência:

Luiz Renato Montez Guidoni

Av. Lacerda Franco 206, Cambuci - São Paulo - SP - Cep 01536-000

Email: guidoni@medscape.com

Fax: 1132095553

\section{INTRODUÇÃO}

Os transplantes renais, com o aperfeiçoamento da técnica operatória, concomitante ao melhor entendimento do sistema imune, juntamente com osurgimento de novas drogas, fizeram com que os pacientes com insuficiência renal crônica terminal aumentassem a chance de sucesso no pós-transplante. ${ }^{1}$ As complicações urológicas têm acompanhado os transplantes renais desde as primeiras publicações e as taxas de mortalidade causadas por estas complicações têm diminuído progressivamente. ${ }^{2,3}$ Essas complicações são divididas em ureterais e infecção urinária. ${ }^{4}$

Dentre as ureterais, as principais são: fístula urinária, obstrução ureteral e refluxo vésico-ureteral, sendo que nos últimos dez anos a incidência de complicações urológicas baixou para taxas entre $2 \%$ e $10 \%$ excluída a infecção urinária como causa ${ }^{5,6}$. Análise da literatura demonstra ser a fístula urinária a principal complicação do transplante renal com freqüência, morbidade e mortalidade variáveis conforme a técnica utilizada e o serviço que a realizou.? A incidência de fístulas urinárias oscila entre $5 \%$ e $15 \%$ e os percentuais de morbidade relacionada às fístulas oscila entre $13 \%$ e $100 \%{ }^{8,9}$

Essas fístulas têm múltiplas causas: insuficiência vascular, tipo de técnica cirúrgica empregada para restabelecer o trato urinário, surto de rejeições, infecções urinárias e no local do enxerto, hematoma no local do enxerto, entre outras. ${ }^{10}$ A segunda complicação ureteral mais freqüente é a obstrução ureteral que varia de $0,3 \%$ a $7,5 \%$ podendo ser precoce, secundária a edema e hematoma locais, linfocele ou isquemia ureteral ou tardia, devido a fibrose 
retroperitoneal, compressão extrínseca e isquemia crônica do ureter por episódios repetidos de rejeição. ${ }^{6,11,12}$ A terceira complicação ureteral é o refluxo vésico-ureteral com incidência em torno de $0,3 \%$, principalmente relacionada à realização de túnel submucoso pequeno e pressões intravesicais elevadas durante a micção devido a obstrução infravesical. ${ }^{13}$ Não existe padronização em relação ao tratamento destas complicações, em razão do elevado número de fatores causais relacionados a cada complicação e devido à preferência do cirurgião em tratar cada uma destas.

\section{OBJETIVO}

Analisar as complicações ureterais nos pacientes pediátricos submetidos a transplante renal, relacionando com a sobrevida do paciente e do enxerto.

\section{MÉTODOS}

Foi realizado um estudo transversal retrospectivo com 84 casos consecutivos de transplante renal pediátrico nos departamentos de cirurgia e pediatria do Hospital Central da Faculdade de Ciências Médicas da Santa Casa de São Paulo, no período de outubro de 1985 a abril de 2005. Dentre estes, havia 50 enxertos de doador vivo e 34 de doador cadáver. A idade dos pacientes variou entre um e 17 anos com média de 11,2 anos. Todos os enxertos foram realizados de forma extraperitoneal, com a colocação do enxerto na fossa ilíaca, sem predileção pelo lado. A anastomose vésico-ureteral (técnica extra-vesical) foi realizada após a revascularização do enxerto.

As complicações ureterais após o transplante foram diagnosticadas de diversas formas: piora da função renal, presença de ureterohidronefrose (detectada à ultrassonografia de controle) do enxerto, alterações clínicas como queda do débito urinário, presença de abaulamento na fossa ilíaca (onde foi colocado o enxerto) e presença de secreção abundante na ferida operatória. Em relação ao refluxo, não houve busca ativa, porém na presença de infecção do trato urinário de repetição, piora da função renal e alteração na micção, foi realizado cistografia miccional e / ou cintilografia renal. Estas complicações foram analisadas quanto a idade, sexo, etiologia da insuficiência renal, tipo de doador, diagnóstico das complicações, tratamento instituído e evolução pós-operatória.

\section{RESULTADOS}

Dos 84 pacientes analisados, nove apresentaram complicações ureterais compondo um total de $10,7 \%$ (gráfico 1), sendo oito fístulas $(9,5 \%)$ e uma estenose ureteral $(1,1 \%)$. Todas as fístulas ocorreram entre o segundo e o trigésimo sexto dia pósoperatório, em média no décimo primeiro dia. Três pacientes foram tratados através de reimplante ureteral extravesical e nos outros seis foram utilizados os ureteres primitivos dos receptores. Não houve casos de refluxo vésico-ureteral para o rim transplantado. Não foram observados óbitos relacionados às complicações ureterais.

Todas as complicações ocorreram em pacientes que haviam recebido enxerto de doador vivo.

A distribuição destes pacientes em relação ao sexo mostrou-se homogênea, (55,5\% do sexo masculino e $44,4 \%$ do sexo feminino) não havendo diferenças dignas de nota quando comparados aos pacientes que evoluíram sem complicações.

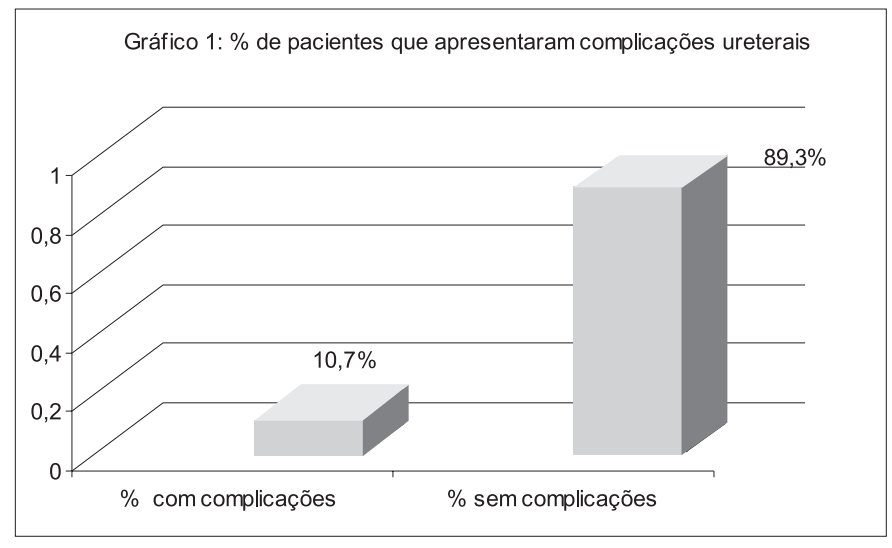

Sete pacientes do estudo apresentaram evolução satisfatória do ponto de vista das complicações ureterais; contudo, dos pacientes que tiveram complicações, dois sofreram perda do enxerto após um ano de realização do transplante, sendo associada à rejeição crônica, apesar do uso de imunossupressores. De todos os pacientes que tiveram complicações ureterais, não foi observado nenhum óbito em seus seguimentos, relacionado às complicações descritas no presente trabalho.

Gráfico 2: Freqüência das complicações ureterais

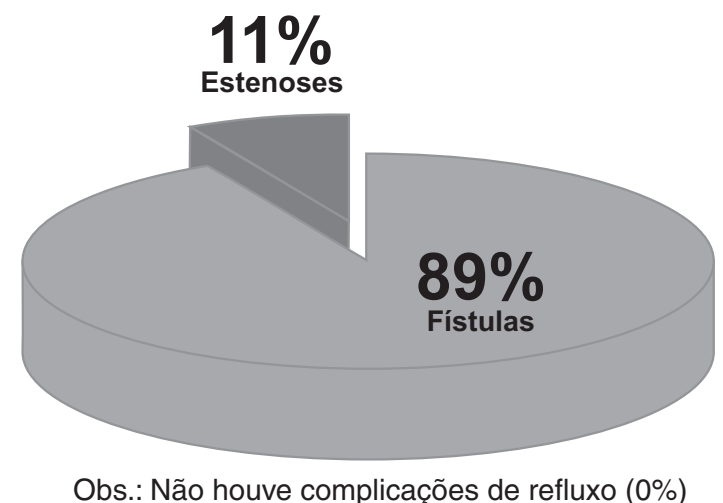

\section{DISCUSSÃO}

Com base nos bons resultados na técnica de implante ureteral extravesical elegemos esta técnica para realização deste procedimento em nossos transplantes; optou-se por essa técnica no reimplante ureteral em três pacientes devido à facilidade técnica observada durante a re-operação para correção das complicações. Porém, em outros seis pacientes encontrou-se dificuldade para a realização do implante ureteral extravesical, optando-se pela utilização do ureter primitivo do receptor para realização de anastomose com o ureter do doador, técnica essa que pode ser indicada no caso de falha de qualquer outro método empregado previamente. ${ }^{14}$

A baixa quantidade de trabalhos na literatura mundial descrevendo complicações cirúrgicas de transplante renal em crianças foi um impulso para o presente estudo. A maior série encontrada foi a do egípcio Shokeir ${ }^{15}$ Em seu relato, em 250 transplantes intervivos, houve 10 casos de fístula urinária, 11 de estenose ureteral e um de litíase ureteral, somando $8,8 \%$ de todos os casos. 
Fístulas de baixo débito, (quatro pacientes), foram tratadas de modo endoscópico. Quando estavam associadas à necrose, foi necessária operação aberta. Em casos de estenose, quando esta era recente, o tratamento endoscópico foi possível, porém a cirurgia aberta foi necessária em casos tardios ou graves. Também demonstra que nenhum paciente ou enxerto teve a sobrevida alterada devido à complicação.

Outro trabalho sobre o tema, com 166 transplantes, sendo 144 com doador cadáver e 22 com doador vivo. ${ }^{16}$ Desse total, houve 11 complicações $(6,6 \%)$, sendo sete casos de fístulas urinárias, duas estenoses ureterais, uma litíase ureteral e um refluxo vésico-ureteral. $\mathrm{O}$ tratamento foi endoscópico em três fístulas, cirurgia aberta em três fístulas, duas estenoses e no refluxo. Um caso de fístula e o de litíase foram tratados conservadoramente. De acordo com o sexo, houve complicações em $10,8 \%$ dos garotos e $5,5 \%$ das garotas.

\section{CONCLUSÃO}

A principal complicação ureteral foi a fístula urinária, que assim como as outras complicações foram passíveis de tratamento, não interferindo diretamente com a sobrevida do paciente e do enxerto.

\section{ABSTRACT}

Introduction: The main ureteral complications after kidney transplantation are urinary leakage, stenosis and reflux, varying from 2 to $10 \%$. In general, these complications do not cause the graft loss or fatal outcome. Purpose: Analyze the ureteral complications in kidney transplanted children in a single institution, and relating patient to graft survival. Methods: A transversal retrospective study with 84 consecutive pediatric kidney recipients at Santa Casa de São Paulo, performed between 1985 and 2005 (ages ranged from 1 to 17 years old) was conduced. Results: From an amount of 84 patients, 9 presented ureteral complications (10.7\%), being 8 cases of urinary leakage (9.5\%), and 1 ureteral stenosis (1.1\%). All the urinary leakage occurred between the second and thirty-sixth postoperative day (mean 11 days). There was no vesicoureteral reflux case reported. Only two patients (1.7\%) presented graft dysfunction developed during the first postoperative year. Conclusion: The ureteral complications led to little morbidity in terms of graft dysfunction and patient survival.

Keywords: Complications; ureter; renal transplantation; kidney; living donor; child.

\section{REFERÊNCIAS}

1. Nahas,W.C. - Transplante Renal com Doador “Cadáver”: Relação de Aspectos do Doador, do Receptor e do Ato Cirúrgico Com a Evolução do Doente. São Paulo, 1993. ( Tese - Doutorado - Faculdade de Medicina da Universidade de São Paulo ).

2. Küss,R.; Tenturier, J.; Milliez, P. - Quelques Essais de Greffes de Rein Chez L'homme. Mém. Acad. Chir., 77: 755-64. 1951

3. Pompeo, A.C.L.- Fístulas Urinárias: Análise de 55 Casos em 1000 Transplantes Renais. São Paulo, 1986. (Tese - Doutorado - Faculdade De Medicina Da Universidade De São Paulo).

4. Al-Askasi, S. - Urological Aspects Of Renal Transplantation. In: Rapaport, F.T. \& Dausset, J. - Human Tsplantation. New York, Gune \& Stratton, 1968. P. 100-15.

5. Irvine, A.H.; Leahy,C.F.; Vogelfanger, I.J. - Management Of The Ureter In Renal Trasnplantation. Br. J. Surg. 74: 922-5, 1987.

6. Shoskes. D.A.; Hanbury, D.; Cranston,D.; Morris, P,J. - Urological Complications In 1000 Consective Renal Transplant Recipients. J. Urol., 153:18-21, 1995.

7. Campos-Freire, G. - Complicações Urológicas do Alotransplante Renal. São Paulo, 1976. (Tese - Livre Docência - Faculdade de Medicina da Universidade de São Paulo).

8. Martin. D.C.; Mims, M.M.; Kaufman, J.J.; Goodwin, W.E. - The Ureter in Renal Transplantation. J. Urol., 101:680-7, 1969.

9. Barroso Junior., U.; Lipay, M.A.S.; D’ávila, C.L.R.; Picanço Neto, J.M.; Abbud Filho,
M.; Zerati Filho, M. - Complicações Cirúrgicas Pós-Transplantes Renais. Análise de 356 Casos. J. Bras. Urol., 23:71-6 1997.

10. Brandina, L. - Estudo Comparativo de Fístula Urinária no Transplante Renal Com Anastomose Pielo-Piélica E Com Ureteroneocistostomia Extra-Vesical. São Paulo, 1982. (Tese - Livre Docência - Faculdade de Medicina da Universidade de São Paulo).

11. Leary, F.J.; Woods, H.E.; Deweerd, J.H - Urologic Problems In Renal Transplantation. Arch. Surg., 110:1124-6, 1975

12. Lamaster, D.; Katzberg, R.W.; Confer, D.J.; Slaysman, M.L. - Ureteropelvic Fibrosis In Renal Transplants: Radiographic Manifestation. Ajr Am. J. Roentgenol., 135:7982,1980

13. Campos-Freire, G. - Complicações Urológicas do Alotransplante Renal. São Paulo, 1976. (Tese - Livre Docência - Faculdade de Medicina da Universidade de São Paulo).

14. Naraghi, R.M. \& Jordan, M. L. - Surgical Complications. In: Shapiro, R.; Simmons, R.L.; Starzl, T.E. - Renal Transplantation. Pennsylvania, Appleton \& Lange, 1997. P.267-313.

15. Shokeir, A; Osman, Y; Ali-El-Dein, B; El-Husseini, A; El-Mekresh, M; ShehabEl-Din, A - Surgical complications in live-donor pediatric and adolescent renal transplantation: Study of risk factors. Transplantation. 9(1):33-38, February 2005.

16. Lapointe, S.P..; Charbit, M.; Jan, D.; Lortat-Jacob, S.; Michel, J.; Beurton, D.; et al. - Urological Complications After Renal Transplantation Using Ureteroureteral Anastomosis In Children. J Urol 166(3):1046-1048, September 2001. 